\title{
Numerical simulation of profile control by clay particles after polymer flooding
}

\author{
Feng Qihong, ${ }^{1 *}$, Shi Shubin ${ }^{1,3}$, Wang Sen ${ }^{1}$ and Zheng $\mathrm{Lu}^{4}$ \\ ${ }^{1}$ School of Petroleum Engineering, China University of Petroleum, Qingdao, Shandong 266555, China \\ ${ }^{2}$ School of Petroleum Engineering, China University of Petroleum, Beijing 102249, China \\ ${ }^{3}$ Shengli Oil Production Research Institute, SINOPEC, Dongying, Shandong 257000, China \\ ${ }^{4}$ Bozhong Operation Company, CNOOC, Tianjin 300452, China
}

(C) China University of Petroleum (Beijing) and Springer-Verlag Berlin Heidelberg 2010

\begin{abstract}
A three-dimensional, two-phase, five-component mathematical model has been developed to describe flow characteristics of clay particles and flocs in the profile control process, in which the clay particle suspension is injected into the formation to react with residual polymer. This model considers the reaction of clay particles with residual polymer, apparent viscosity of the mixture, retention of clay particles and flocs, as well as the decline in porosity and permeability caused by the retention of clay particles and flocs. A finite difference method is used to discretize the equation for each component in the model. The Runge-Kutta method is used to solve the polymer flow equation, and operator splitting algorithms are used to split the flow equation for clay particles into a hyperbolic equation for convection and a parabolic equation for diffusion, which effectively ensures excellent precision, high speed and good stability. The numerical simulation had been applied successfully in the 4-P1920 unit of the Lamadian Oilfield to forecast the blocking capacity of clay particle suspension and to optimize the injection parameters.
\end{abstract}

Key words: Clay particles, flocs, detention, operator splitting algorithms, numerical simulation

\section{Introduction}

Polymer flooding greatly improves areal and vertical sweep efficiencies of injected water and ameliorates displacement efficiency. However, a fingering phenomenon occurs in the follow-up water flooding process due to the formation heterogeneity and unfavorable fluid mobility ratio. This triggers a high flow rate of injected water in the reservoir and then leads to a low sweep efficiency (Allen and Boger, 1988; Pavone, 1989; Seright, 1991; Sorbie et al, 1991). To improve the sweep efficiency of injected water after polymer flooding, Xiong et al (2005) and Dai et al (2006) developed residual polymer reutilization technology. Flocs will be formed after the reutilization agents react with residual polymers. This will block thief zones and prevent cross flow. The agent used for reaction with residual polymers remaining after polymer flooding is mainly clay. However, most previous studies have focused on laboratory experiments (Xiong et al, 2005; Dai et al, 2006). In this study, a mathematical model is developed to characterize the migration of polymers, clay particles and flocs and their plugging mechanisms. This is of considerable significance in injection profile control and parameter optimization after polymer flooding.

*Corresponding author. email: fengqihong@126.com

Received January 25, 2010

\section{Mathematical model}

To simplify the mathematical model, the following assumptions are made:

1) Flow is isothermal in the reservoir and isothermal chemical reactions occur during flooding.

2) Polymers, clay particles, and flocs are components in the water phase.

3) The influence of chemical agents on the water density is negligible. The chemical agents only affect the water viscosity and water relative permeability, but have no influence on the oil phase.

4) Clay particles and flocs have no effect on the mass conservation of the water phase.

5) Polymer adsorption on the rock surface follows the Langmuir equation, and the adsorption is irreversible.

6) Phase equilibrium is achieved nearly instantaneously.

7) Fluid flow in porous media follows Darcy' Law after the clay particles and flocs deposit in the pores.

For two-phase flow in porous medium, the flow equation for oil phase is given by:

$$
\nabla \cdot\left[\frac{k k_{\mathrm{ro}}}{\mu_{\mathrm{o}} B_{\mathrm{o}}}\left(\nabla p_{\mathrm{o}}-\gamma_{\mathrm{o}} \nabla D\right)\right]+q_{\mathrm{o}}=\frac{\partial}{\partial t}\left(\frac{\phi S_{\mathrm{o}}}{B_{\mathrm{o}}}\right)
$$

The flow equation for water phase is given by: 


$$
\nabla \cdot\left[\frac{k k_{\mathrm{rw}}}{R_{\mathrm{k}} \mu_{\mathrm{w}} B_{\mathrm{w}}}\left(\nabla p_{\mathrm{w}}-\rho_{\mathrm{w}} g \nabla D\right)\right]+q_{\mathrm{w}}=\frac{\partial}{\partial t}\left(\frac{\phi S_{\mathrm{w}}}{B_{\mathrm{w}}}\right)
$$

The flow equation for polymer component is given by:

$$
\begin{aligned}
& \nabla \cdot\left[\frac{k k_{\mathrm{rw}}}{R_{\mathrm{k}} \mu_{\mathrm{w}} B_{\mathrm{w}}}\left(\nabla p_{\mathrm{w}}-\rho_{\mathrm{w}} g \nabla D\right) C_{\mathrm{p}}\right]+q_{\mathrm{p}}+R_{\mathrm{p}} \\
& =\frac{\partial}{\partial t}\left[\frac{\phi_{\mathrm{p}}\left(S_{\mathrm{w}} C_{\mathrm{p}}+C_{\mathrm{pads}}\right)}{B_{\mathrm{w}}}\right]
\end{aligned}
$$

The flow equation for clay particles is given by:

$$
\begin{aligned}
& \nabla \cdot\left[\frac{k k_{\mathrm{rw}}}{R_{\mathrm{k}} \mu_{\mathrm{w}} B_{\mathrm{w}}}\left(\nabla p_{\mathrm{w}}-\rho_{\mathrm{w}} g \nabla D\right) C_{\mathrm{cp}}\right]+q_{\mathrm{cp}} \\
& =\frac{\partial}{\partial t}\left(\delta_{\mathrm{cp}}\right)+R_{\mathrm{cp}}+\frac{\partial}{\partial t}\left(\frac{\phi_{\mathrm{cp}} C_{\mathrm{cp}} S_{\mathrm{w}}}{B_{\mathrm{w}}}\right)
\end{aligned}
$$

The flow equation for flocs is given by:

$$
\begin{aligned}
& \nabla \cdot\left[\frac{k k_{\mathrm{rw}}}{R_{\mathrm{k}} \mu_{\mathrm{w}} B_{\mathrm{w}}}\left(\nabla p_{\mathrm{w}}-\rho_{\mathrm{w}} g \nabla D\right) C_{\mathrm{fl}}\right]+R_{\mathrm{fl}} \\
& =\frac{\partial}{\partial t}\left(\delta_{\mathrm{fl}}\right)+\frac{\partial}{\partial t}\left(\frac{\phi_{\mathrm{fl}} C_{\mathrm{fl}} S_{\mathrm{w}}}{B_{\mathrm{w}}}\right)
\end{aligned}
$$

where subscripts $\mathrm{o}, \mathrm{w}, \mathrm{p}, \mathrm{cp}$, and fl denote oil, water, polymer, clay particles, and flocs, respectively; $D$ is the depth from a certain horizontal surface, $\mathrm{m} ; p_{\mathrm{o}}$ and $p_{\mathrm{w}}$ are the oil-phase pressure and water-phase pressure, respectively, $10^{-1} \mathrm{MPa} ; S_{\mathrm{o}}$ and $S_{\mathrm{w}}$ are the oil saturation and water saturation, respectively, fraction; $k$ is the formation permeability, $\mu \mathrm{m}^{2} ; k_{\mathrm{ro}}$ and $k_{\mathrm{rw}}$ are the relative permeability to oil and water, respectively, fraction; $\mu_{\mathrm{o}}$ and $\mu_{\mathrm{w}}$ are the oil and water viscosities, respectively, $\mathrm{mPa} \cdot \mathrm{s} ; B_{\mathrm{o}}$ is the oil formation volume factor and $B_{\mathrm{w}}$ is the water formation volume factor, $\mathrm{m}^{3} / \mathrm{m}^{3} ; \rho_{\mathrm{o}}$ and $\rho_{\mathrm{w}}$ are the oil and water densities, $\mathrm{g} / \mathrm{cm}^{3} ; \delta$ is the formation porosity, fraction; $R_{\mathrm{k}}$ is the permeability reduction factor, fraction; $C_{\mathrm{p}}, C_{\mathrm{cp}}$, and $C_{\mathrm{fl}}$ are the mass concentrations of polymer, clay particles, and flocs in the water phase, respectively, fraction; $\delta_{\mathrm{p}}, \delta_{\mathrm{cp}}$, and $\delta_{\mathrm{fl}}$ are the fractions of pore volume occupied by polymer, clay particles, and flocs, respectively, to the bulk volume, fraction; $R_{\mathrm{p}}$ and $R_{\mathrm{cp}}$ are the volumes of polymer and clay particles which react with each other in unit time per unit apparent rock volume, $1 / \mathrm{s} ; R_{\mathrm{ff}}$ is the volume of flocs generated in unit time per unit apparent rock volume, $1 / \mathrm{s} ; \delta_{\mathrm{cp}}$ and $\delta_{\mathrm{fl}}$ are the volumes of clay particles and flocs remaining in unit pore volume, respectively, fraction.

\section{Additional equations}

1) Kinetic equation

To simplify the problem, the bridging between clay particles and polymer is viewed as a reaction process, which can be written as:

$$
n \mathrm{cp}+\mathrm{p} \rightarrow \mathrm{fl}
$$

During the reaction, the residual polymer remaining in the formation reacts with clay particles to generate flocs. The kinetic equation used to describe the reaction is as follows:

$$
\left\{\begin{array}{c}
R_{\mathrm{cp}}=\frac{\mathrm{d} C_{\mathrm{cp}}}{\mathrm{d} t}=-k n C_{\mathrm{cp}} C_{\mathrm{p}} \\
R_{\mathrm{p}}=\frac{\mathrm{d} C_{\mathrm{p}}}{\mathrm{d} t}=-k C_{\mathrm{cp}} C_{\mathrm{p}} \\
R_{\mathrm{fl}}=\frac{\mathrm{d} C_{\mathrm{fl}}}{\mathrm{d} t}=k C_{\mathrm{cp}} C_{\mathrm{p}}
\end{array}\right.
$$

where $k$ and $n$ are experimental coefficients, dimensionless.

2) The apparent viscosity of the mixture

The apparent viscosity of the mixture is influenced by each component in the water, and it can be approximately obtained by the following linear equation:

$$
\mu_{\mathrm{T}}=a \mu_{\mathrm{w}}+b \mu_{\mathrm{p}}+c \mu_{\mathrm{cp}}+d \mu_{\mathrm{fl}}
$$

where $\mu_{\mathrm{cp}}$ and $\mu_{\mathrm{fl}}$ are experimentally measured and unaffected by salinity; $a, b, c$ and $d$ are experimental coefficients.

3) The retention equations for clay particles and flocs

The particles with radii less than pore throats would deposit and adsorb on the pore surface (Liu and Hou, 1995), the retention equations for clay particles and flocs are as follows:

$$
\begin{aligned}
& \frac{\partial \delta_{\mathrm{cp}}}{\partial t}=A v_{\mathrm{w}} C_{\mathrm{cp}} \\
& \frac{\partial \delta_{\mathrm{fl}}}{\partial t}=B v_{\mathrm{w}} C_{\mathrm{fl}}
\end{aligned}
$$

where $A$ and $B$ are the retention rate constant of particles on the surface, which are experimentally determined.

4) Decline in the effective porosity and permeability

Clay particles and flocs injected into the reservoir are preferentially transported into the high-capacity channels and may deposit and occupy these pores. This would lead to a reduction in the pore volume (Liu and Hou, 1995). The pore volume decrement equals the volume occupied by flocs and clay particles, and the instantaneous porosity can be expressed as follows:

$$
\phi=\phi_{0}-\delta_{\mathrm{cp}}(x, y, z, t)-\delta_{\mathrm{fl}}(x, y, z, t)
$$

where $\delta_{\mathrm{o}}$ is the initial porosity.

The porosity decline will lead to a decrease in permeability, and the formation permeability after external particle retention can be expressed by the modified Kozeny equation (Liu and Civan, 1993):

$$
K(x, t)=K_{0}\left[D(1-f)+f \frac{\phi(x, y, z, t)}{\phi_{0}}\right]^{3}
$$

with

$$
f=1-\beta\left[\delta_{\mathrm{cp}}(x, y, z, t)+\delta_{\mathrm{fl}}(x, y, z, t)\right]
$$

where $K_{0}$ is the initial permeability; $f$ is the flow efficiency factor; $D$ is a constant for fluid seepage allowed by the plugged pores; and $\beta$ is constant.

5) Phase saturation and capillary pressure equations are as 
follows (Liu, 2006):

$$
\begin{aligned}
& S_{\mathrm{o}}+S_{\mathrm{w}}=1 \\
& p_{\text {cow }}=p_{\mathrm{o}}-p_{\mathrm{w}}=p_{\mathrm{c}}\left(S_{\mathrm{w}}, \sigma_{\mathrm{wo}}\right)
\end{aligned}
$$

where $\sigma_{\text {wo }}$ and $p_{\text {cow }}$ are the interface tension and capillary pressure on the interface between the oil phase and the water phase.

In addition, equations of adsorption, inaccessible pore volume, and residual resistance factor are also included in the model. The treatments of these equations are similar to those in numerical simulation of polymer flooding, so details about the process are not given here. More details can be found in the reference (Yuan, 1991).

\section{Numerical solution}

Solution to the mathematical model is obtained by the following procedure: (1) Solve the mass conservation equations of oil and water. (2) Solve the concentration of each component in the water phase by substituting the pressure and saturation into the equations for each component. (3) Solve the retention of clay particles and flocs according to their concentrations in water, hence the reservoir porosity and permeability fields can be updated by retention distribution. (4) Repeat steps (2) and (3) by the iteration method until the resulting sequence converges to the solution on the time step. (5) Go to the next time step until the simulation end.

\subsection{Solution to the flow equations for oil and water}

An unconditionally stable implicit backward difference scheme is used to discretize the flow equations for oil and water, of which nonlinear parameters are treated by a semiimplicit method, and finally pressure and saturation of each grid can be solved from the system of linear equations by the Preconditioned Conjugate Gradient Method (Li and Gu, 2009).

\subsection{Solution to the flow equation for the polymer component}

After obtaining the distributions of pressure and saturation, the polymer flow equation can be solved by an explicit method. The conventional second-order central difference method would lead to severe numerical dispersion, so a high-order difference method is essential. Expanded by a total differential method and discretized by a classical RungeKutta method (Li et al, 2004; Iserles, 2005), the flow equation for the polymer component can be solved.

\subsection{Solution to the flow equation for clay particles}

The most effective method of solving the complicated convection-diffusion equation of clay particles is an operator splitting algorithm (Pedro et al, 2003; Feng et al, 2006). The convection-diffusion equation is split into a hyperbolic equation for convection and a parabolic equation for diffusion. Furthermore, the difference equations are obtained by the MacCormack scheme (Yu and Tang, 2003) and fractional predictor-corrector scheme (Yanenko, 1992; Lu and Guan, 1987), respectively. The concentration of clay particles in the suspension obtained from the hyperbolic equation can be used as the initial value of the parabolic equation, and then the solution to the concentration at $n+1$ time step will be attained.

\subsection{Solution to the flow equation for flocs}

The solution method for the conservation equation of flocs is similar to that for the flow equation of clay particles.

\section{Field applications}

\subsection{Basic description and production history match of the pilot test area}

The Lamadian Oilfield, which has been developed since 1973, is an edge-water-drive reservoir consisting of an anticline and a gas cap. It has experienced following production phases: flow period, oil pumping, profile control, flood pattern modification, secondary infilling, and polymer drive. At present the water cut is more than $92 \%$.

The 4-P1920 unit, located at the northwest of the West Lamadian Oilfield Block, contains six injection wells and twelve production wells drilled on 237-m spacing (between the injection well and the production well). The reservoir unit has an average effective thickness of $13.2 \mathrm{~m}$, gross pore volume of approximately $196.5 \times 10^{4} \mathrm{~m}^{3}$, and original oil in place (OOIP) of $105.9 \times 10^{4}$ tonnes. The oil recovery is $46.4 \%$ OOIP at present. In addition, the oil in the reservoir unit was first produced by injection of polymer solution and then started being displaced by water from May, 2007.

Before prediction, it is necessary to use history matching to certify the geological model. Relevant parameters used in the process are shown in Table 1. Matching errors of these main production performance parameters, OOIP, water cut, cumulative oil production of the unit and water cut of important single wells, are less than 5\%; moreover, the distributions of remaining oil and residual polymer are in good accordance with field information, which demonstrates that the model of 4-P1920 unit closely reflects the real geological conditions. This lays a solid foundation for the further study of the injection effect of clay particle suspension.

Table 1 Parameters used in history matching

\begin{tabular}{cc}
\hline Parameters & Value \\
\hline Polymer molecular weight, g/mol & $10^{7}$ \\
Polymer solution concentration, $\mathrm{mg} / \mathrm{L}$ & 1000 \\
Polymer solution viscosity, $\mathrm{mPa} \cdot \mathrm{s}$ & 40 \\
Polymer solution injection volume, PV & 0.6 \\
Water viscosity, $\mathrm{mPa} \cdot \mathrm{s}$ & 0.42 \\
Water density, $\mathrm{kg} / \mathrm{m}^{3}$ & 1000 \\
Oil viscosity, $\mathrm{mPa} \cdot \mathrm{s}$ & 10 \\
Oil density, $\mathrm{kg} / \mathrm{m}^{3}$ & 864 \\
\hline
\end{tabular}




\subsection{Dynamic prediction of clay particle injection}

Clay particle suspension was injected into the 4-P1920 unit from September, 2007 to November, 2007. A total of $0.0158 \mathrm{PV}$ of clay particle suspension was injected into the unit, with an average clay particle concentration of $2.65 \%$. Water has been injected into the 4-P1920 unit to displace the oil since the clay particle suspension injection was finished. Field performance prediction shows that the incremental oil is 5,335 tonnes and the oil recovery increases by about $0.50 \%$ OOIP after introducing the clay particle suspension into the 4-P120 unit. The water cut curve for the pilot test area is shown in Fig. 1.

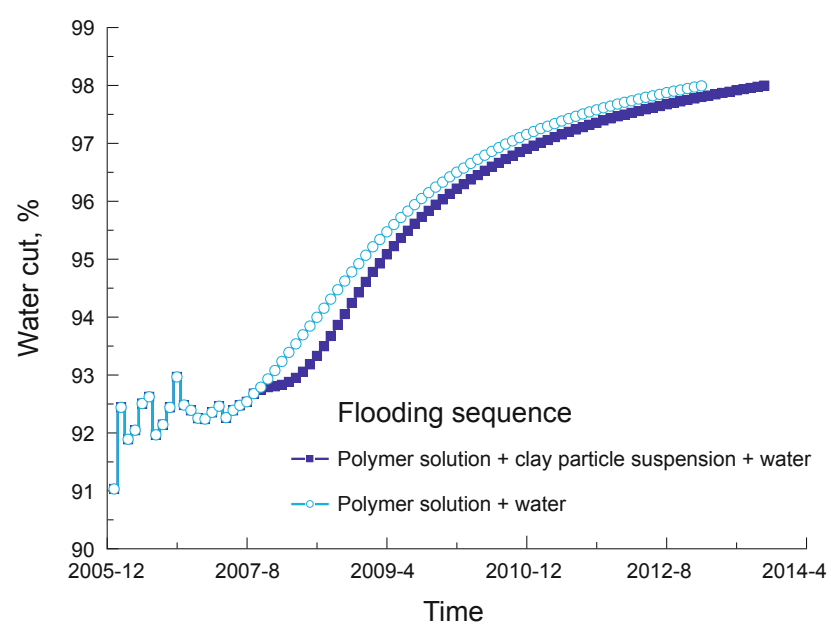

Fig. 1 Water cut curve after clay particle suspension injected into the 4-P1920 unit

\subsection{Project optimization of clay particle injection}

Based on the history matching of 4-P1920 unit, injection projects of polymer and clay particles were designed and optimized.

\subsubsection{Optimization of timing of clay particle injection in the polymer flooding period}

After introducing a specific volume of polymer solution, 0.013 PV 3\% clay particle suspension is injected into the 4-P1920 unit. Then this is followed by a water flush. Details about these cases are shown in Table 2. The incremental oil recovery values for the six cases are calculated when the water cut reaches $98 \%$, and are also listed in Table 2.

Table 2 shows that the incremental oil recovery is the highest for case A4 compared with the case without clay particle suspension. When the volume of polymer solution injected into the formation is less than $0.4 \mathrm{PV}$, the concentration of polymer remaining in the formation is very low. Therefore, only a small number of flocs are formed in the formation when the clay particles are injected, which cannot block off the thief zones. When the volume of the polymer solution injected is more than $0.4 \mathrm{PV}$, the mobility of crude oil decreases and the remaining oil saturation is less, despite the number of flocs generated being higher, the incremental oil recovery is lower.
Table 2 Simulation cases for optimization of injection timing in the polymer flooding period

\begin{tabular}{|c|c|c|}
\hline Case & Flooding sequence & $\begin{array}{l}\text { Incremental oil } \\
\text { recovery, } \%\end{array}$ \\
\hline A1 & $\begin{array}{l}0.1 \mathrm{PV} \text { polymer solution }+0.013 \mathrm{PV} \text { clay } \\
\text { particle suspension }+ \text { water drive }\end{array}$ & 0.36 \\
\hline A2 & $\begin{array}{l}0.2 \mathrm{PV} \text { polymer solution }+0.013 \mathrm{PV} \text { clay } \\
\text { particle suspension }+ \text { water drive }\end{array}$ & 0.65 \\
\hline $\mathrm{A} 3$ & $\begin{array}{l}0.3 \mathrm{PV} \text { polymer solution }+0.013 \mathrm{PV} \text { clay } \\
\text { particle suspension }+ \text { water drive }\end{array}$ & 0.76 \\
\hline A4 & $\begin{array}{l}0.4 \mathrm{PV} \text { polymer solution }+0.013 \mathrm{PV} \text { clay } \\
\text { particle suspension }+ \text { water drive }\end{array}$ & 0.78 \\
\hline A5 & $\begin{array}{c}0.5 \mathrm{PV} \text { polymer solution }+0.013 \mathrm{PV} \text { clay } \\
\text { particle suspension }+ \text { water drive }\end{array}$ & 0.68 \\
\hline A6 & $\begin{array}{l}0.7 \mathrm{PV} \text { polymer solution }+0.013 \mathrm{PV} \text { clay } \\
\text { particle suspension }+ \text { water drive }\end{array}$ & 0.50 \\
\hline
\end{tabular}

\subsubsection{Optimization of timing of clay particle injection in water flooding period}

The flooding sequence of simulation cases is as follows: polymer solution, water slug, 0.013 PV 3\% clay particle suspension, and water drive (until water cut reaches 98\%). This flooding sequence was repeated to study the effects of polymer solution volume and water slug size. The incremental oil recovery values for these cases are calculated when the water cut reaches 98\%, which are shown in Fig. 2.

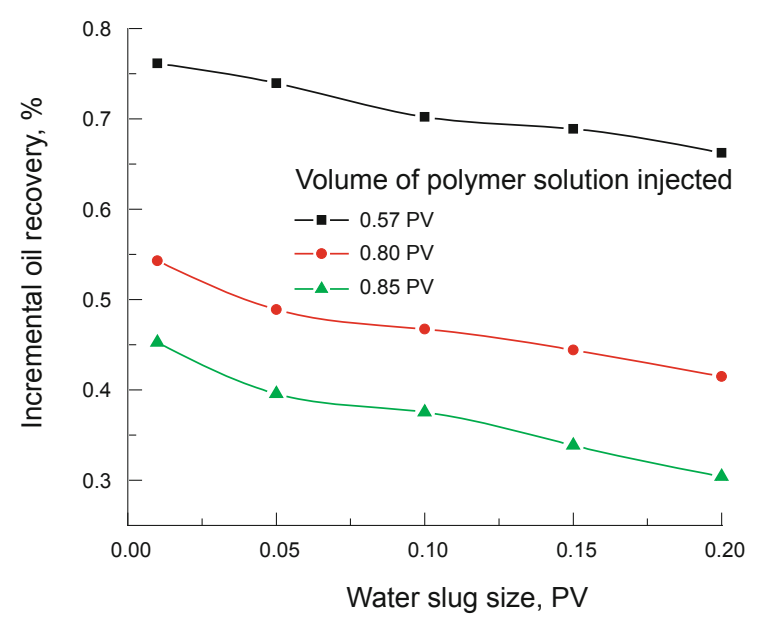

Fig. 2 Incremental oil recovery for clay particle suspension injection in different following water flooding period

Fig. 2 shows that the bigger the water slug size (after polymer flooding) is, the lower the incremental oil recovery is. With an increase in the water slug size, more residual polymer is displaced by water. This leads to a relative low concentration of polymer remaining in the formation near the well and thus only a small number of flocs are formed when the clay particle suspension is injected. Therefore, the injection profile is not improved effectively. Fig. 2 also illustrates that the injection profile is significantly improved 
when the clay particle suspension is injected after a $0.01 \mathrm{PV}$ water slug following $0.57 \mathrm{PV}$ polymer solution. An additional 8,051 tonnes of oil was recovered.

\subsubsection{Optimization of injection volume}

After introducing a specific volume of polymer solution (0.57, 0.80 , and $0.85 \mathrm{PV}$, respectively) followed by a 0.05 PV water slug, a 3\% clay particle suspension is injected into 4-P1920 unit.Then water is injected until the water cut of the produced fluid reaches $98 \%$. The incremental oil recovery values for these cases are obtained and shown in Fig. 3.

Fig. 3 shows that under the same conditions the incremental oil recovery increases and then decreases with increasing pore volume of clay particle suspension injected into the unit. This may be explained as follows: The swept volume increases with the injected pore volume of clay particle suspension, so more flocs are formed in pore space, providing an effective blockage for the formation. The oil recovery increases by $3.61 \%$ OOIP (i.e. 38,244 tonnes of oil) when 0.051 PV clay particle suspension is injected. However, the subsequent injection of clay particle suspension will lead to a reduction in incremental oil recovery for the reason that those redundant clay particles which have not reacted with residual polymer will block off relatively low permeability zones and cause formation damage.

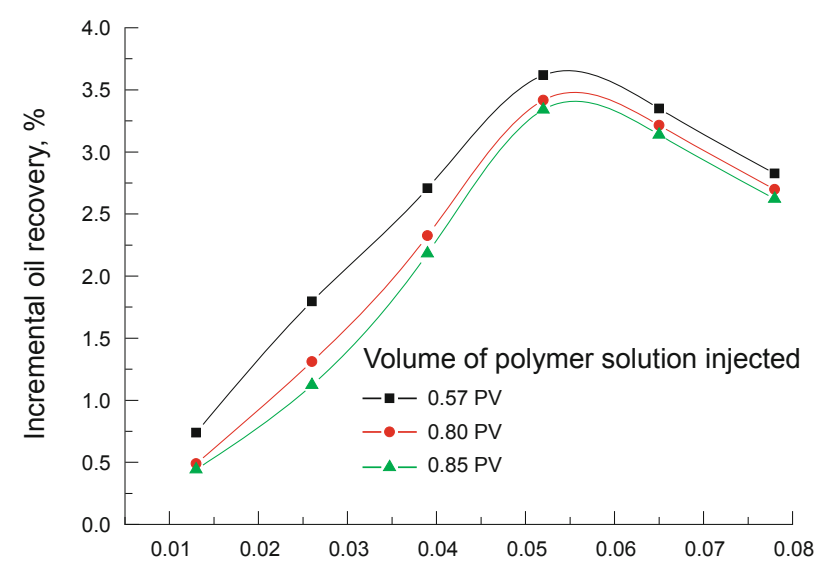

The total volume of clay particle suspension injected, PV

Fig. 3 Incremental oil recovery versus injection volume of clay particle suspension

\subsubsection{Optimization of injection rate}

After introducing $0.8 \mathrm{PV}$ polymer solution followed by a 0.05 PV water slug into the formation, 0.052 PV 3\% clay particle suspension is injected into at a specified injection rate $\left(2,000,1,500,1,200,1,000\right.$, and $750 \mathrm{~m}^{3} / \mathrm{d}$, respectively). Then water is injected to displace the oil. The incremental oil recovery values for these cases obtained when the water cut reaches $98 \%$ are shown in Fig. 4.

Fig. 4 shows that under the same conditions the higher the injection rate is, the lower the incremental oil recovery is. At low injection rates, clay particles will enter the deep formation and react with the residual polymer to form flocs. This will block off not only the high permeability zones but also the secondary pores around the high permeability zones, which will improve the blockage effect. Fig. 4 also shows that the oil recovery is the highest (increased by $3.54 \%$ OOIP, i.e. 37,503 tonnes of recoverable oil) at the injection rate of $750 \mathrm{~m}^{3} / \mathrm{d}$. But actually the injection rate should be neither too high nor too low, which depends on the oil production rate.

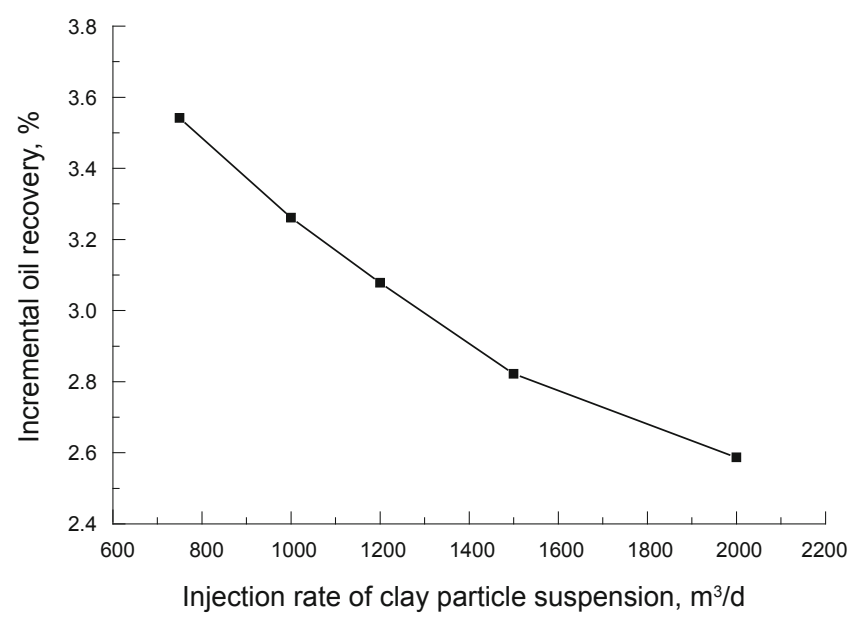

Fig. 4 The effect of injection rate of clay particle suspension on oil recovery

\section{Conclusions}

1) A three-dimensional, two-phase, five-component mathematical model was developed, which can be applied to numerical simulation of profile control by clay particles that injected into the formation after polymer flooding. The model takes the following factors into consideration: the reaction of clay particles with residual polymer, apparent viscosity of the mixture, retention of clay particles and flocs, as well as the decline of porosity and permeability caused by the detention of clay particles and flocs.

2) The Runge-Kutta method was used to solve the polymer flow equation, and operator splitting algorithms were used to discretize the flow equations for clay particles and flocs, which effectively ensure excellent precision, high speed, and good stability.

3) The numerical simulation was applied successfully in the 4-P1920 unit of the Lamadian Oilfield. The injection parameters of clay particles were optimized for the unit, which included injection timing in polymer flooding period \& water flooding period, injection volume and injection rate.

\section{Acknowledgements}

The authors are grateful for the financial support from the National High Technology Research and Development Program of China (863 Program) ( 2007AA06200) and "Taishan Scholars" Construction Project (No. ts20070704).

\section{References}

Allen E and Boger D V. The influence of rheological properties on mobility control in polymer-augmented waterflooding. Paper SPE 18097 presented at SPE Annual Technical Conference and Exhibition held in Houston, Texas, October 2-5, 1988

Dai C L, Zhao F L, Xiao J H, et al. Studies of the reutilization techniques of the residual polymer in formation after polymer flooding. Journal of Xi'an Shiyou University (Natural Science Edition). 2006. 21(6): 
56-60 (in Chinese)

Feng Q H, Zhang G, Tao Y, et al. Study of fast simulation method for flowing gel driving. Journal of China University of Petroleum. 2006. 30(6): 63-66 (in Chinese)

Iserles A. A First Course in the Numerical Analysis of Differential Equations. Translated by Liu X Y and Liu X S. Beijing: Tsinghua University Press. 2005. 32-50 (in Chinese)

Li S X and Gu J W. Reservoir Numerical Simulation. Dongying: China University of Petroleum Press. 2009. 127-131 (in Chinese)

Li W G, Huang B J, Tong D K, et al. Numerical Calculation Method. Dongying: China University of Petroleum Press. 2004. 243-249 (in Chinese)

Liu X and Civan F. Characterization and prediction of formation damage in two-phase flow systems. Paper SPE 25429 presented at the Production Operations Symposium held in Oklahoma City, March 21-23, 1993.

Liu X P and Hou L P. A mathematical model for simulating formation damage due to solid particle invasion during water injection. Journal of Jianghan Petroleum Institute. 1995. 17(2): 69-73 (in Chinese)

Liu Y Z. EOR Technology After Polymer Flooding. Beijing: Petroleum Industry Press. 2006. 102-125 (in Chinese)

Lu J P and Guan Z. Numerical Methods for Partial Differential Equations. Beijing: Tsinghua University Press. 1987: 100-130 (in Chinese)

Pavone D. Observation and correlations for immiscible viscous-fingering experiments. Paper SPE 19670 presented at SPE Annual Technical
Conference and Exhibition held in San Antonio, October 8-11, 1989

Pedro G R, Manuel K S and Francisco J M M. Streamline methodology using an efficient operator splitting for accurate modeling of capillarity and gravity effects. Paper SPE 79693 presented at SPE Reservoir Simulation Symposium held in Houston, Texas, February 3-5, 2003

Seright R S. Impact of dispersion on gel placement for profile control. SPE Reservoir Engineering. 1991. 6(3): 343-352 (SPE 20127)

Sorbie K S, Tsibuklis N B and Dwebi A. Experimental testing of mobility prediction in averaged models of viscous fingering. Paper SPE 22617 presented at SPE Annual Technical Conference and Exhibition held in Dallas, Texas, October 6-9, 1991

Xiong S C, Wang Y F, He Y, et al. The study on IOR after polymer flooding of Gudao Oilfield. Fault-block Oil \& Gas Field. 2005. 12(3): 38-40 (in Chinese)

Yanenko N N. The Method of Fractional Steps - The Solution of Problems of Mathematical Physics in Several Variables. Translated by Zhou B X and Lin P. Beijing: Science Press. 1992: 19-47 (in Chinese)

Yu D H and Tang H Z. Numerical Methods for Differential Equations. Beijing: Science Press. 2003: 218-219 (in Chinese)

Yuan S Y. A mathematical model of high permeability channel blockage in a heterogeneous reservoir by in-situ polymer gelation process. Acta Petrolei Sinica. 1991. 12(1): 49-58 (in Chinese)

(Edited by Sun Yanhua) 